\title{
SISTEMA DE CLASSIFICAÇÃO GEOMORFOMÉTRICA BASEADO EM UMA ARQUITETURA SEQUENCIAL EM DUAS ETAPAS: ÁRVORE DE DECISÃO E CLASSIFICADOR ESPECTRAL, NO PARQUE NACIONAL SERRA DA CANASTRA GEOMORPHOMETRIC CLASSIFICATION SYSTEM BASED ON A TWO-STAGE SEQUENTIAL ARCHITECTURE: DECISION TREE AND SPECTRAL CLASSIFIER, IN THE SERRA DA CANASTRA NATIONAL PARK
}

Vinicius Vasconcelos
Embrapa Cerrados - BR 020, km 18 - Rod. Brasília-Fortaleza, Planaltina/DF - Caixa Postal 08223 - CEP 73310-970-
e-mail: vinicius.vascoza@gmail.com

Osmar Abílio de Carvalho Júnior

Universidade de Brasília, Laboratório de Sistemas de Informações Espaciais, Departamento de Geografia, ICC Ala Norte, Campus Universitário Darcy Ribeiro, Brasilia/ DF - CEP 70910-900-e-mail: osmarjr@unb.br

Eder de Souza Martins Embrapa Cerrados, BR 020, km 18, Rod. Brasília-Fortaleza, Planaltina/DF - Caixa Postal 08223 - CEP 73310-970 e-mail:eder@cpac.embrapa.br

Antônio Felipe Couto Junior Universidade de Brasilia, Faculdade UnB Planaltina, Planaltina/DF - CEP 73300-000 e-mail: antoniofelipejr@gmail.com

Renato Fontes Guimarães

Universidade de Brasilia, Laboratório de Sistemas de Informações Espaciais, Departamento de Geografia, ICC Ala Norte, Campus Universitário Darcy Ribeiro, Brasília/DF - CEP 70910-900 - e-mail: renatofg@unb.br

Roberto Arnaldo Trancoso Gomes

Universidade de Brasília, Laboratório de Sistemas de Informações Espaciais, Departamento de Geografia, ICC Ala Norte, Campus Universitário Darcy Ribeiro - Brasília/DF - CEP 70910-900 - e-mail: robertogomes@unb.br

Informações sobre o Artigo

Data de Recebimento:

$16 / 01 / 2012$

Data de Aprovação:

04/07/2012

Palavras-chave:

Assinatura Geomorfométrica; Formas de Terreno; Elementos do Terreno

Keywords:

Geomorphometric Signature; Landforms; Landforms Elements

\section{Resumo}

Geomorfometria é uma ciência interdisciplinar (que combina a ciência da terra, matemática e computação) que descreve a superfície terrestre como uma representação numérica com descritores quantitativos. Assim, a geomorfometria evolui com os métodos computacionais presentes em Sistema de Informação Geográfica (SIG), a fim de estudar inúmeros problemas, tais como: susceptibilidade deslizamento de terra, hidrogramas de bacia, erosão do solo, distribuição da vegetação, entre outros. Um tópico de pesquisa importante na Geomorfometria é extrair e classificar formas de relevo a partir do Modelo Digital de Elevação (MDE), que é um pré-requisito para melhorar a compreensão da dinâmica dos geossistemas naturais. Assim, os métodos 
de classificação automática têm sido desenvolvidos, a fim de obter resultados que asseguram um processamento de dados rápido, preciso e reprodutível por indivíduos independentes. Vários parâmetros geomorfométricos têm sido descritos na tentativa de caracterizar a paisagem, destacando a altimetria e suas derivações de primeira e segunda ordem. Isso mostra que os atributos apresentam diferentes níveis de generalização e aplicação que devem ser usadas em condições específicas na estratificação da paisagem. Este trabalho tem como objetivo propor um método de classificação sequencial das formas do relevo considerando as diferenças inerentes dos atributos de terreno na Serra da Canastra - MG. O método proposto consiste em um sistema de classificação baseado em uma arquitetura em duas etapas sequenciais: (a) classificação por árvore de decisão dos dados de altitude e de declividade, e (b) subdivisão de classes anteriores pelo classificador espectral Spectral Angle Mapper (SAM), utilizando atributos de curvatura. Na classificação pelo SAM (segunda etapa) é necessário estabelecer uma assinatura geomorfométrica para cada forma de terreno, que é descrita por um espectro composto pelas seguintes curvaturas: (a) vertical, (b) longitudinal, (c) de transversal, (d) mínimo, (e), máximo, e (f) horizontal. A determinação da assinatura é obtida a partir de um método desenvolvido para o processamento de imagens de sensoriamento remoto hiperespectral contendo os seguintes passos: (a) redução espectral, (b) redução espacial, e (c) identificação de assinaturas geomorfométricas utilizando visualizador n-dimensional. Os resultados demonstram diferentes classes de forma de terreno que representam unidades distintas e homogêneas no Parque Nacional da Serra da Canastra. A combinação dos dois métodos melhora os resultados porque cada procedimento identifica diferentes aspectos dos padrões da paisagem em diferentes níveis de escala. A classificação pelo SAM usando as assinaturas geomorfométrica com todos os tipos de curvatura demonstrou ser sensível na detecção das variações presentes ao longo da vertente descritos pelas suas inflexões espectrais.

\begin{abstract}
Geomorphometry is an interdisciplinary science (combining Earth science, mathematics and computation) that describe land surface as a numerical representation with quantitative descriptors. Thus, the geomorphometry evolves with the computational methods inserted into Geographic Information System (GIS) in order to study innumerable problems, as such: Susceptibility, soil erosion, vegetation distribution among others. An important research topic in the Geomorphometry is to extract and classify landforms from Digital Elevation Model (DEM), which is a prerequisite to improve the understanding of the spatiotemporal dynamics into natural geosystems. Thus, automatic classifications methods have been developed in order to achieve results that ensure fast data processing, accurate and reproducible by independent individuals. Several geomorphometric parameters have been described in an attempt to characterize the landscape, highlighting the altimetry and its first-order and second-order derivative. These attributes show different levels of generalization and applicability that should be used for specific conditions in the landscape stratification. This paper aims to propose a hierarchical classification method of landform considering the inherent differences of the terrain attributes in the Serra da Canastra- MG. The proposed method consists of a classification system based on two-stage sequential architecture: (a) decision tree classification of altitude and slope data; and (b) subdivision of previous classes from the spectral classifier Spectral Angle Mapper (SAM) using curvature attributes. In SAM classification (second stage) is necessary to establish a geomorphmetric signature for each landform, which is described by a spectrum composed by the following curvatures: (a) profile, (b) longitudinal, (c)cross-section, (d) minimum, (e) maximum, and (f) plan. The signature determination is obtained from a method developed for hyperspectral image processing in remote sensing containing the following steps: (a) reduction of the spectrum size, (b) reduction of the spatial size, and (c) identification of geomorphometric signatures using n-dimensional viewer. The results demonstrate different landform classes that represent distinct homogenous units in the Serra da Canastra National Park. The combination of two methods improves the results because each procedure identifies different aspects of the landscape patterns and scale levels. SAM classification using geomorphometric signature enables a detection of hillside variations described by its spectral inflections.
\end{abstract}




\section{Introdução}

A superfíce da Terra pode ser subdividida em entidades espaciais que se caracterizam por diferentes tamanho, forma, orientação e posição geográfica, que resultam de diversos processos integrados ao longo do tempo (geológico, hidrológico, ecológico, pedológico, antrópico entre outros) (Macmillan e Shary, 2009). Assim, as feições do relevo infere sobre as dinâmicas que controlam a distribuição espacial dos materiais e energia, como: regime da dinâmica da água, textura do solo, presença de sedimentos inconsolidados, desenvolvimento pedogenético, entre outros.

Muitos estudos têm sido realizados para obter uma descrição detalhada das formas de terreno com o propósito de compreender a evolução da paisagem. Nesta perspectiva, consolida-se o campo da ciência denominada de "(Geo) morfometria" que analisa a superfície topográfica de forma quantitativa. O termo "geo" é adicionado ao termo comumente usado "morfométria" com o propósito de distinguir as métricas das formas de terreno com as adotadas em outras áreas do conhecimento como zoologia e sedimentologia (Evans, 1972). Esta disciplina também é conhecida como "análise de terreno" ou "modelagem digital de terreno" (Lane et al., 1998; Pike, 2000). A geomorfometria obteve um acentuado desenvolvimento com a expansão do uso do Modelo Digital de Elevação (MDE) e dos seus atributos de terrenos, que são usualmente processados em Sistemas de Informação Geográfica (SIG) (Evans, 1984; Evans e Mcclean, 1995; Wood, 1996; Shimidt e Dikau, 1999; Valeriano e Carvalho junior, 2003; Smith et al., 2006; Minár e Evans, 2008, Pike et al., 2009). Portanto, a descrição numérica da superfície torna-se uma fonte de informação cada vez mais confiável para a estimativa de diversos fenômenos, como por exemplo: hidrogramas de bacias, erosão do solo, movimento de massa, fluxo de água entre outros.

Os métodos de classificação automatizada das superfícies de terreno adotam como descritores os atributos derivados de MDEs (Evans, 1972; O’Neill e Mark, 1987). Nestes procedimentos são considerados os fatores de escala, tamanho e forma. Os principais métodos desenvolvidos utilizam uma chave de classificação dos atributos de terreno considerando um conjunto de regras pré-estabelecidas. Nesta concepção, Wood (1996) propõe um método que extrai e classifica seis Formas de Terreno (FTs): Plane, Channel, Ridge, Pass, Peake Pit. O método considera uma combinação específica dos pares de curvaturas Longitudinal/Transversal e Mínima/Máxima a depender da declividade da região a ser classificada. Assim, as curvaturas Longitudinal/Transversal são apenas utilizadas quando o relevo apresenta uma declividade mais acentuada. Consequentemente, as curvaturas de Mínima e Máxima são utilizadas em áreas de relevo mais suave. Desta forma, a combinação das curvaturas apresenta uma relação excludente de acordo com o relevo que será modelado.
Os métodos mais atuais possibilitaram a subdivisão das FTs em Elementos de Terreno (ET) (Landforms Elements), que são um conjunto de parcelas de um tipo de relevo relativamente homogênea em relação à forma (curvaturas de perfil e de plano), inclinação (declividade), orientação ou exposição (aspecto ou radiação solar) e posicionamento na paisagem (Macmillan e Shary, 2009). Entretanto observa-se que a classificação das FTs e ETs ainda se baseiam em critérios que são controlados por uma prévia compartimentação morfológica do terreno o que dificulta visualizar as continuidades das Formas de Terreno e dos Elementos de Terreno. Schmidt e Hewitt (2004), por exemplo, desenvolveram um procedimento obtendo diferentes ETs utilizando como critério a posição da paisagem, dividindo-a em áreas planas e em áreas dissecadas a partir da curvatura tangencial, vertical, mínima e máxima. Dragut e Blaschke (2006) optaram por segmentar os objetos do MDE relativamente homogêneos em vários níveis geomorfológicos utilizando curvatura de plano e curvatura vertical.

Uma maneira de representar os atributos de terreno presentes em uma determinada forma de terreno é a partir do estabelecimento de uma curva padrão que o descreve. No presente artigo é adotado o conceito de "assinatura geomorfométrica" uma adaptação do termo "assinatura geométrica" proposto por Pike (1988), que consiste na formulação de um espectro das medidas topográficas capaz de distinguir as diferentes paisagens. Assim, cada célula da grade (unidade de terreno) é descrita por uma curva dos atributos de terreno (espectro) que pode ser comparada com curvas específicas de formas de relevo (assinaturas). Esta abordagem conduz ao emprego de técnicas de reconhecimento de padrões a partir de métodos estatísticos multivariados comumente empregados no processamento digital de imagens de sensoriamento remoto (Brown et al. 1998).

No entanto, para obter uma análise profícua deve-se primeiramente realizar uma análise das informações morfométricas a serem utilizadas. Os atributos de terreno possuem níveis de generalização e aplicabilidade diferentes, devendo ser utilizados com propósitos específicos nas estratificações da paisagem. Os atributos mais utilizados para a classificação consistem na altimetria e dos seus produtos provenientes de sua derivação, como: primeira derivada (declividade e aspecto) e segunda derivada (curvaturas). Entre estes atributos de terreno, a altimetria caracteriza-se por ser uma superfície suavizada evidenciando fragmentos homogêneos relativamente maiores que a declividade e a curvatura. A declividade representa a taxa de variação espacial da altimetria que permite salientar as quebras no relevo. Por fim, as curvaturas representam uma taxa de variação espacial da declividade ou aspecto evidenciando um detalhamento das informações anteriores. Portanto, os atributos de terreno provenientes da derivação da superfície devem ser considerados separadamente por representar feições em escala e detalhamento distintas. 
O presente trabalho possui como objetivo descrever as FTs e os ETs a partir de classificação sequencial dos atributos de terreno. Desta forma, uma classificação em duas etapas é proposta: (a) classificação por árvore de decisão das componentes relativas à altimetria e da sua primeira derivada (declividade), e (b) classificação espectral pelo método Spectral Angle Mapper (SAM) das assinaturas geomorfométricas formadas pelos atributos de terreno relativos à segunda derivada do relevo (curvaturas). A área de estudo é o Chapadão do Zagaia na Serra da Canastra que possui relevância ambiental e geográfica por conter a nascente do rio São Francisco. Diferentes estudos utilizando atributos do relevo têm sido aplicados em áreas de conservação, como: Parque Nacional da Chapada dos Veadeiros (Carvalho Júnior et al., 2001), Parque Nacional da Serra dos Órgãos (Martins et al., 2007; Oliveira et al., 2007), Parque Nacional da Serra do Cipó (Peloso e Shimabukuro, 2010) e Parque Nacional da Serra da Canastra (Couto Junior et al., 2010).

\section{Área de Estudo}

O Parque Nacional da Serra da Canastra é uma Unidade de Conservação (UC) que consiste em uma eficaz estratégia de garantir o acesso dos recursos naturais pela sociedade. Segundo ICMBio (2005) a Serra da Canastra - SC pode ser dividida em dois compartimentos de relevo: o Chapadão do Diamante e o Chapadão do Zagaia. O Chapadão do Zagaia - CZ está localizada no estado de Minas Gerais entre os municípios de São Roque de Minas e Sacramento com 248,55km² entre as coordenadas UTM (23S) 7.768.140,065 e 7.772.153,796 $\mathrm{N}-297.995,131$ e $331.167,371$ E (Figura 1).
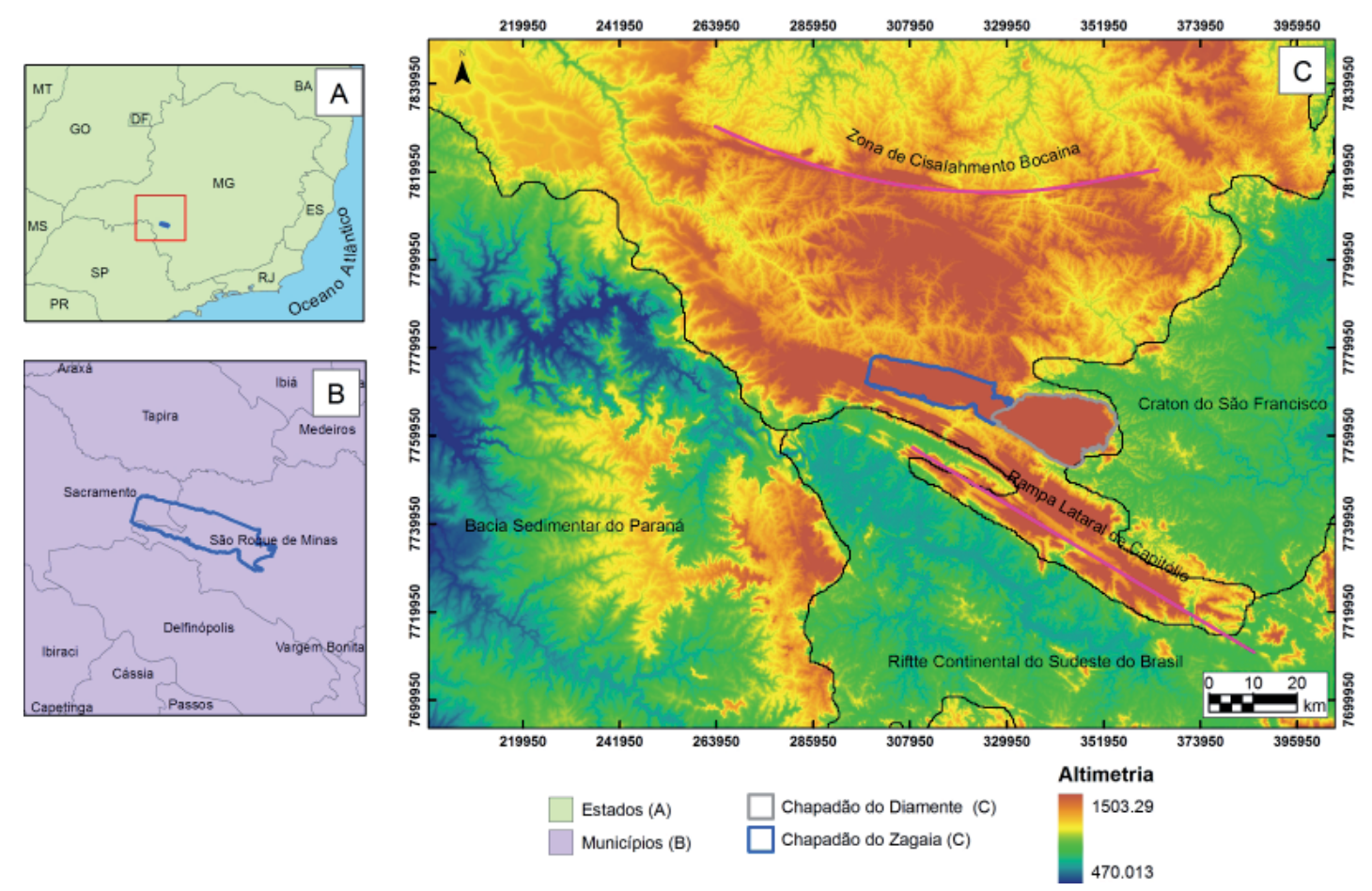

Figura 1- Localização do Chapadão do Zagaia no contexto estadual (A) municipal (B) e morfoestrutural (C).

A Faixa Brasília, onde se encontra o CZ, é um sistema orogenético Neoproterozóico situado entre os crátons Amazônicos e São Francisco, desenvolvidos no contexto dos eventos colisionais que culminaram da amalgamação do supercontinente Gondwana ao final do Neoproterozóico (Almeida, 1977). A compartimentação tectônica é definida de leste para oeste, pelos terrenos que se acrescionaram à borda ocidental do Cráton do São Francisco iniciado a cerca de 900 Ma com a fragmentação do supercontinente Rodínia (Valeriano et al., 2004). Na sua margem ocidental se depositaram os grupos Canastra, Ibiá, Paranoá, Vazante, Bambuí, Araxá e Andre- lândia. O CZ compreende uma região no Grupo Canastra entre a Rampa lateral de Capitólio e a zona de cisalhamento da Bocaina com compartimentação tectônica denominada Domínio Externo (Valeriano et al., 1995).

A região segundo Brasil (1983) é parte do domínio Morfoestruturas dos Remanescentes de Cadeias Dobradas composto pelo subdomínio da Região dos planaltos da Canastra separando-se em duas Unidades: Patamares da Canastra e Serras. Este domínio integra conjuntos de modelado resultantes da exumação de estruturas dobradas ao longo de 
vários ciclos geotectônicos. Ross (2006) considera que a SC está inserida dentro da morfoestrutura dos planaltos e serras de Goiás-Minas, associada à faixa Brasília de dobramento com serras residuais das antigas dobras com alinhamento de cristas sustentadas com frequência por rochas metamórficas. Ele atribui a essa região formas de relevo como os morros alongados e cristas em anticlinais e em sinclinais.

De acordo com Ab'Saber (1970), a região pertence ao domínio dos chapadões tropicais interiores com Cerrados e Matas de Galeria. Apresentam espécies das seguintes famílias: Fabaceae, Mimosaceae, Eriocaulaceae, Orchidaceae, Myrtaceae e Malpighiaceae (Romero e Nakajima, 1999). As fitofisionomias da Serra da Canastra são classificadas como Campo Sujo, Campo Limpo, Cerrado Sentido Restrito, Ambientes Rupestres, Vegetação Hidromórfica (Couto Junior et al., 2010).

O clima regional é caracterizado pela sazonalidade, com chuvas no verão e inverno seco. A temperatura média do mês mais frio é inferior a $18^{\circ} \mathrm{C}$ e a do mês mais quente não ultrapassa $22^{\circ} \mathrm{C}$ (ICMbio, 2005). A área apresenta características de pluviosidade anual entre 1.000 e $1.500 \mathrm{~mm}$. O trimestre de dezembro a fevereiro, além de mais chuvoso, é o de maior excedente hídrico e o de escoamento superficial mais ativo (Souza, 1993). Além disso, a porção do alto São Francisco está embutida na região de clima Tropical do Brasil Central, onde predominam temperaturas sub-quentes e clima semi-úmido com quatro a cinco meses secos (ANA, 2002).

\section{Materiais e Métodos}

O presente trabalho propõe um método para a compartimentação do relevo considerando duas etapas de classificação de dados geomorfométricos: (a) classificação por árvore de decisão considerando a altimetria e a declividade; e (b) classificação pelo método SAM (Spectral Angle Mapper) de assinaturas geomorfométricas compostas pelo conjunto de seis tipos de curvaturas de terreno. Desta forma, o MDE e sua primeira derivada permitem compartimentar as maiores feições geomorfológicas. As curvaturas por consistirem na segunda derivada do terreno são mais sensíveis as variações sendo adequadas para detectar subclasses dentro das áreas identificadas na primeira etapa. Esta estratégia apresenta como vantagem obter uma classificação hierárquica considerando as características distintas dos atributos de terreno.

O MDE utilizado é proveniente da missão Shuttle Radar Topography Mission (SRTM) possuindo uma resolução espacial de 3 arcsec ( $~ 90$ metros) com datum WGS84 horizontal e vertical e precisão vertical da ordem de 5 metros (Smith e Sandwell, 2003). Esta missão utilizou a Space Shuttle Endeavour em fevereiro de 2000 com dois radares de abertura sintética relativos à banda $\mathrm{C}(5,6 \mathrm{~cm} ; \mathrm{C}-\mathrm{RADAR})$ e a banda X (3,1 cm; X-RADAR) (FARR et al., 2007). Os dados topográficos foram adquiridos de um sobrevôo único que abrange $80 \%$ da superfície terrestre em apenas 11 dias, entre as latitudes $60^{\circ} \mathrm{N}$ e $57^{\circ} \mathrm{S}$. O sistema de aquisição de dados contínua (dia e noite, com cobertura de nuvens) garantiu a obtenção de dados homogêneos de todo o mundo, tornando os dados provenientes do SRTM uma importante ferramenta para estudos da superfície terrestre (Van Zyl, 2001; Rabus et al., 2003).

Apesar da alta qualidade dos dados SRTM, eventualmente, persistem algumas limitações, especificamente: (a) falta de dados em algumas áreas (vazios); (b) presença de picos e de vórtices; (c) e má definição dos corpos d'água e das linhas de costas (Jarvis et al., 2004; Lu et al., 2004; Rabus et al., 2003). Para detectar possíveis valores ruidosos foi aplicado o seguinte procedimento (Guimarães et al., 2005): (a) filtro de mediana; (b) subtração do resultado do filtro pelo dado original; (c) retirada dos valores com variação de $10 \mathrm{~m}$ decorrente da falta de informação; e (c) interpolação pelo método Topogrid proposto por Hutchinson (1989). A partir do SRTM foram geradas as imagens relativas aos atributos de terreno cujas formulações estão expressas na tabela 1 .

Tabela 1- Fórmulas da Declividade e Curvaturas (Wood, 1996).

\begin{tabular}{l|l|c}
\hline \multicolumn{1}{c}{ Curvatura } & \multicolumn{1}{c}{ Fórmula } & Referência \\
\hline Declividade & $\arctan \left(\sqrt{d^{2}+e^{2}}\right)$ & (Wood, 1996) \\
\hline Vertical & $\frac{-200\left(a d^{2}+b e^{2}+c d e\right.}{\left(e^{2}+d^{2}\right)\left(1+d^{2}+e^{2}\right)^{2}}$ & (Evans, 1979) \\
Longitudinal & $-2 \frac{\left(a d^{2}+b e^{2}+c d e\right)}{d^{2}+e^{2}}$ & (Wood, 1996) \\
Transversal & $-2 \frac{\left(b d^{2}+a e^{2}-c d e\right)}{d^{2}+e^{2}}$ & (Wood, 1996) \\
Minima & $-a-b-\sqrt{(a-b)^{2}+c^{2}}$ & (Young, 1978) \\
Máxima & $-a-b+\sqrt{(a-b)^{2}+c^{2}}$ & (Young, 1978) \\
Horizontal & $\frac{200\left(b d^{2}+a e^{2}-c d e\right)}{\left(e^{2}+d^{2}\right)^{1,5}}$ & (Evans, 1979) \\
\hline
\end{tabular}

\section{Classificação por Árvore de Decisão}

Com o objetivo de determinar os valores limites entre os ambientes geomorfológicos do CZ realizou-se primeiramente uma análise visual utilizando a técnica de composição colorida. A composição colorida dos atributos de terreno é uma técnica de processamento digital de imagem muito utilizada para realçar as feições e unidades geomorfológicas (Borges et al., 
2007; Hermuche et al., 2003). A composição colorida permite sintetizar numa única imagem, as diferentes informações morfométricas (Oliveira et al., 2007). Dentre as diferentes combinações realizadas a melhor composição é a constituída por: altimetria no canal do Vermelho $(R)$, declividade no canal do Verde $(G)$ e mínima curvatura no canal do Azul $(B)$. A partir da interpretação visual foi possível identificar três ambientes geomorfológicos variando do Rosa (ambientes mais planos), passando pelo Azul (ambientes mais dissecados) até chegar ao verde (ambientes mais íngremes) (Figura 2).

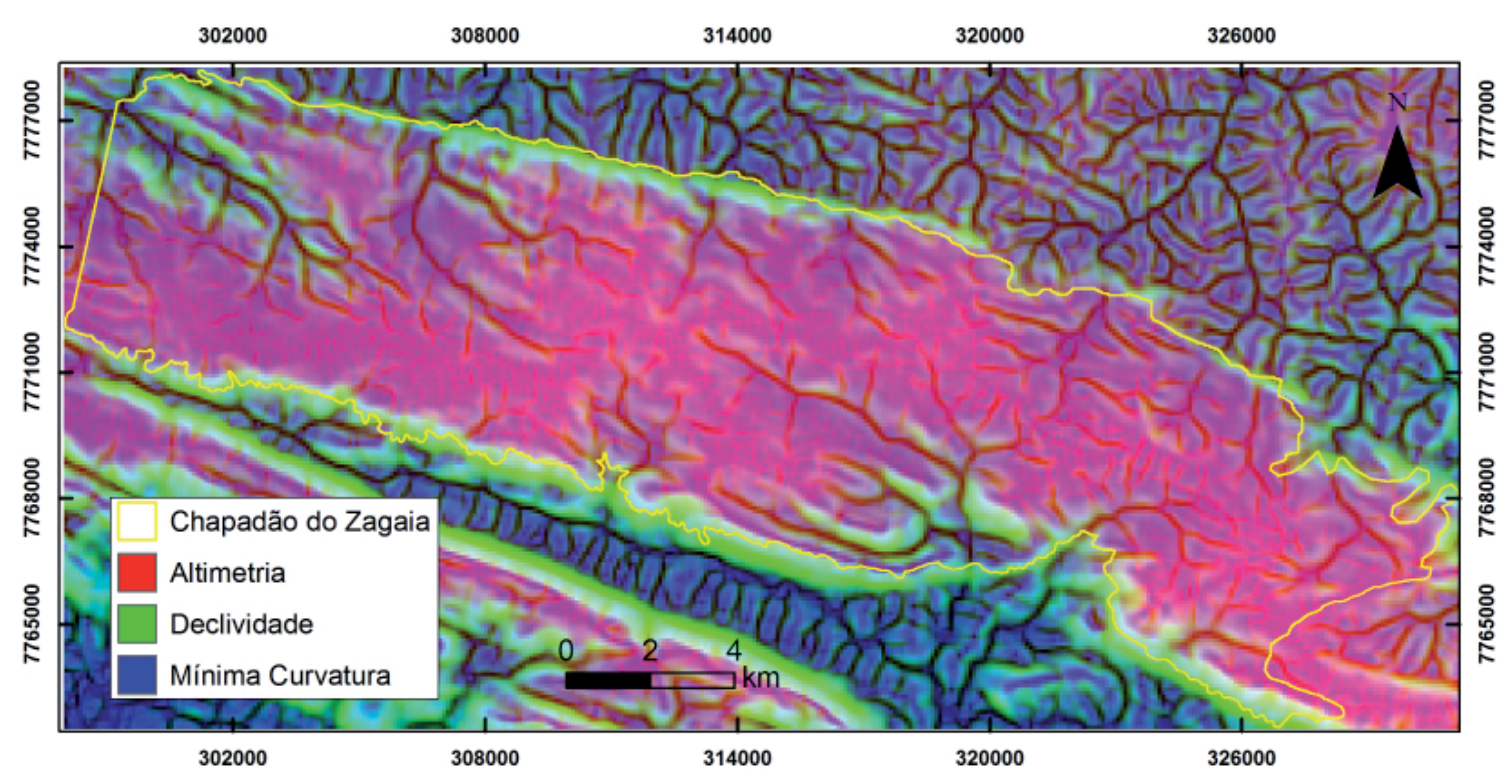

Figura 2 - Composição Colorida de Altimetria (R), Declividade (G) e Mínima Curvatura (B).

A partir do realce digital por Composição Colorida estabeleceu-se critérios para uma classificação utilizando o método de árvore de decisão sobre os dados de altimetria e declividade. A classificação por árvore de decisão estabelece uma regra hierárquica e binária de partição dos valores de atributos de terreno. Este procedimento é composto pelas seguintes componentes (Latorre et al., 2007): (a) um nó raiz formado a partir de todos os dados, (b) um conjunto hierárquico de nós internos denominados partições responsáveis pela tomada de decisão, utilizando teste lógico, que define o próximo nó descendente ou filho, e (c) nós terminais chamados de folhas caracterizados por não possuírem nó descendente. Desta forma, a árvore de decisão binária divide cada nó intermediário em dois nós descendentes: o nó esquerdo (concordante com o teste lógico) e o nó direito (discordante).

\section{Classificação por Assinaturas Geomorfométricas}

Para a confecção das imagens de curvatura foram testadas várias dimensões de janela sendo que a dimensão espacial 11x11 mostrou-se mais adequada permitindo eliminar os pequenos polígonos e amenizar a presença de valores anômalos. Estas imagens foram organizadas em seis bandas na seguinte ordem: (1) Curvatura Vertical, (2) Curvatura Longitudinal, (3) Curvatura Transversal (4) Mínima Curvatura, (5) Máxima Curvatura (6) Curvatura Horizontal. De forma análoga ao agrupamento das imagens multibandas de sensores remotos, as seis imagens de curvatura do terreno são unidas estabelecendo para cada célula um espectro geomorfométrico, que permite caracterizar o ambiente em que está inserido. Conceitualmente, os valores positivos das curvaturas correspondem a terrenos convexos/divergente e os valores negativos a terrenos côncavos/convergente enquanto os valores nulos indicam vertentes retilíneas/ planar. Dentro desse contexto, as seguintes ETs e FTs são apresentadas (Figura 3).
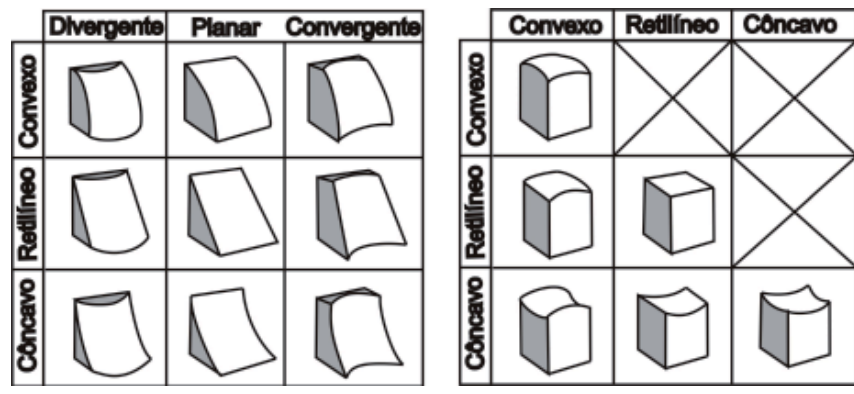

Figura 3 - Elementos de Terreno conforme Evans (1979) utilizando curvatura vertical e horizontal (à esquerda) e Formas de Terreno conforme Wood (1996) a partir dos pares de curvatura Longitudinal e Transversal, e Mínima e Máxima (à direita). 
A assinatura geomorfométrica integra as componentes que descrevem os ETs (Bandas 1 e 6) e os FTs (Bandas 2 a 5) (Figura 4). Essas assinaturas foram normalizadas considerando a divisão pelo seu valor máximo absoluto para padronizar os intervalos entre -1 e 1 . O resultado da normalização proporciona um maior contraste entre as curvas do terreno e um melhor fatiamento das classes: - 1 a - 0,33333 (côncavo/ convergente); - 0,33333 a 0,33333 (retilíneo/planar) e 0,3333 a 1 (convexo/divergente).

Um fator importante a ser considerado antes da normalização é a identificação de valores anômalos eventualmente presentes nas imagens de curvatura. Estes espectros são caracterizados pela presença de valores extremos estando localizados principalmente nos divisores de água, nos vales bem entalhados entre escarpas, e nos canais de drenagem. Estes pixels alteram as etapas subsequentes para a identificação automatizada de espectros devendo ser retirados para a realização das próximas etapas de processamento.

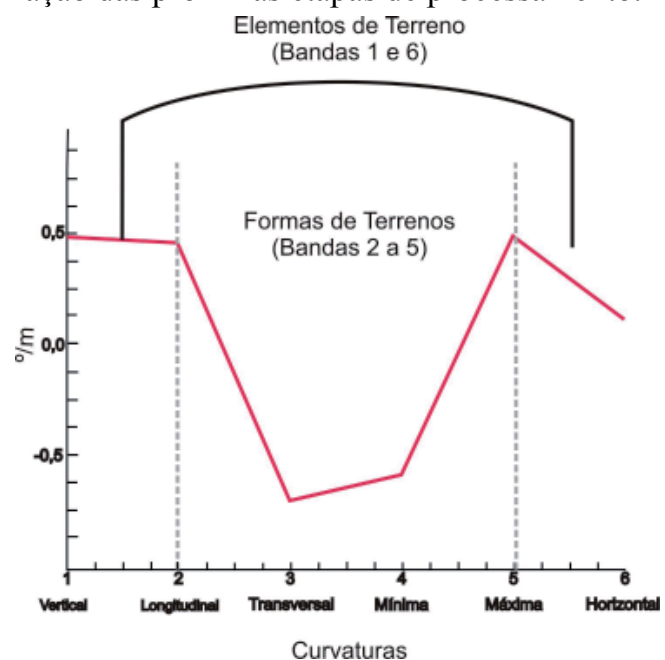

Figura 4 - Exemplo de assinatura geomorfométrica da relação ETs com as FTs.
A partir desta configuração dos dados é possível adotar técnicas de classificação espectral, usualmente, utilizadas em dados de sensoriamento remoto. Neste tipo de classificação, primeiramente, são selecionadas assinaturas espectrais que caracterizam os diferentes ambientes que se desejam identificar. Um procedimento para identificação automatizada destes espectros é o emprego do procedimento proposto por Boardman e Kruse (1994) composta por três etapas: redução da dimensão espectral (Minimum Noise Fraction - MNF), redução da dimensão espacial (índice de pureza do pixel - PPI) e identificação (utilizando um visualizador $n$-dimensional). No presente trabalho a identificação automatizada dos espectros é realizada para cada classe obtida pela árvore de decisão. Os espectros extraídos das quatro classes são agrupados eliminando os espectros redundantes que eventualmente existem em duas classes contíguas.

O método de classificação espectral utilizado foi o Spectral Angle Mapper (SAM) (Kruse et al., 1993) expressa pela seguinte equação:

$$
S A M=\alpha=\cos ^{-1} \frac{\sum_{i=1}^{i=h} R_{i} E_{i}}{\sqrt{\sum_{i=1}^{i=h}\left(E_{i}\right)^{2} \sum_{i=1}^{i=h}\left(R_{i}\right)^{2}}}
$$

Desta forma, temos que o valor do SAM é expresso em radianos, sendo que, quanto menor o ângulo $\alpha$, maior é a similaridade entre as curvas. $\mathrm{O}$ ângulo $\alpha$ determinado pela função arco-cosseno apresenta uma variação entre 0 até 90.

\section{Resultado}

A classificação geomorfométrica foi realizada em uma área de $236,12 \mathrm{~km}^{2}$. Na área de estudo a classificação utilizando a árvore de decisão determina quatro classes (Figura 5, Tabela 2). A detecção automática a partir destas quatro classes definidas permitiu selecionar catorze assinaturas.

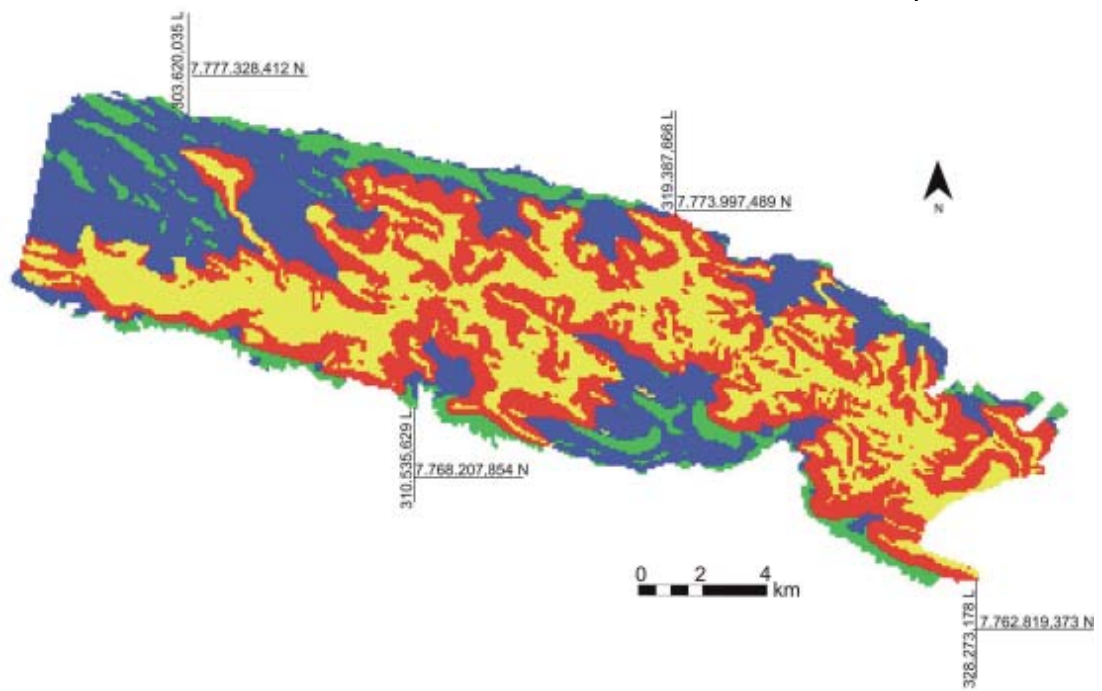

Figura 5 - Classes determinadas a partir de Árvore de Decisão. 
Tabela 2 - Análise descritiva da Declividade (D) e da Altimetria (H) dos Ambientes Geomorfológicos.

\begin{tabular}{|c|c|c|c|c|c|}
\hline & 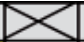 & MIN & MÁX & MÉDIA & DESVIO PADRÃO \\
\hline \multirow{2}{*}{ C4 } & $\mathrm{D}(\%)$ & 0,1 & 7,6 & 4,5 & 1,7 \\
\hline & $H(m)$ & 1270,1 & 1390,0 & 1330,2 & 29,3 \\
\hline \multirow{2}{*}{ C3 } & $\mathrm{D}(\%)$ & 0,5 & 44,4 & 10,7 & 3,9 \\
\hline & $H(m)$ & 1270,0 & 1401,0 & 1311,0 & 26,5 \\
\hline \multirow{2}{*}{$\mathrm{C} 2$} & $D(\%)$ & 0,2 & 18,5 & 10,4 & 4,1 \\
\hline & $H(\mathrm{~m})$ & 1028,2 & 1270,0 & 1213,8 & 52,8 \\
\hline \multirow{2}{*}{$\mathrm{C} 1$} & $\mathrm{D}(\%)$ & 17,9 & 52,9 & 24,9 & 6,1 \\
\hline & $\mathrm{H}(\mathrm{m})$ & 1035,0 & 1269,9 & 1187,9 & 49,3 \\
\hline
\end{tabular}

A classificação espectral pelo SAM delimitou as seguintes Formas do Terreno: Chapadas, Colinas, Bordas, Colos, Depressão de Cabeceira, Depressão Entalhada e Encostas de acordo com Wood (1996). A cada Forma de Terreno foi atribuído um ou mais Elementos de Terreno (Evans, 1979) (Figura 6). Para uma melhor compreensão da relação entre as Formas de Terreno e os seus respectivos Elementos foi sugerida a seguinte nomenclatura (Tabela 3 ).

Tabela 3 - Nomenclatura para o estudo da assinatura geomorfométrica na relação entre as Formas de Terreno e os Elementos das Formas de Terreno.

\begin{tabular}{|c|c|c|}
\hline Formas de Terreno & Elementos de de Terreno & Assinatura Geomorfométrica \\
\hline Chapadas - RT-RT & rt-con & RT-RT_rt-con \\
\hline \multirow{3}{*}{ Colinas - CX-RT } & $c x-p l$ & CX-RT_cX-pl \\
\hline & rt-con & CX-RT_rt-con \\
\hline & $\mathrm{rt}-\mathrm{pl}$ & CX-RT_rt-pl \\
\hline \multirow{2}{*}{ Depresão de Cabeceira - CC-RT } & rt-dir & CC-RT_rt-dir \\
\hline & cc-pl & CC-RT_cC-pl \\
\hline Depresão Entalhada - CC-RT & rt-pl & CC-RT_rt-pl \\
\hline \multirow{2}{*}{ Colos - CX-CC } & $c x-p l$ & CX-CC_cX-pl \\
\hline & cc-pl & CX-CC_cc-pl \\
\hline \multirow{3}{*}{ Bordas CX-RT ou CX-CX } & $c x-p l$ & CX-CX_cx-pl \\
\hline & rt-pl & CX-RT_rt-pl \\
\hline & $\mathrm{cx}-\mathrm{pl}$ & CX-RT_cX-pl \\
\hline \multirow{2}{*}{ Encostas - CC-RT } & rt-pl & CC-RT_rt-pl \\
\hline & cc-pl & CC-RT_cc-pl \\
\hline
\end{tabular}

As Chapadas apresentam uma única assinatura geomorfométrica localizada principalmente nos topos dos planaltos (Figura 7). A Banda 2 (Curvatura Longitudinal) e a Banda 3 (Curvatura Transversal) mantiveram praticamente equivalentes com valores de $0,19691^{\circ} / \mathrm{m}$ e $0,20459 \% / \mathrm{m}$ respectivamente demonstrando uma feição plana. A Banda 4 (Curvatura Mínima) e a Banda 5 (Curvatura Máxima) apresentam uma pequena oscilação, insuficiente para caracterizar um relevo movimentado. Os valores médios de declividade (d) corroboram com essa análise (2,4\%). A Banda 1 (Curvatura Vertical) e a Banda 6 (Curvatura Horizontal) demonstram vertentes retilíneas, mas extremamente convergentes com valor de -0,97693 \% $/ \mathrm{m}$, caracterizando um Elemento de Terreno retilíneo-convergente (rt-con).
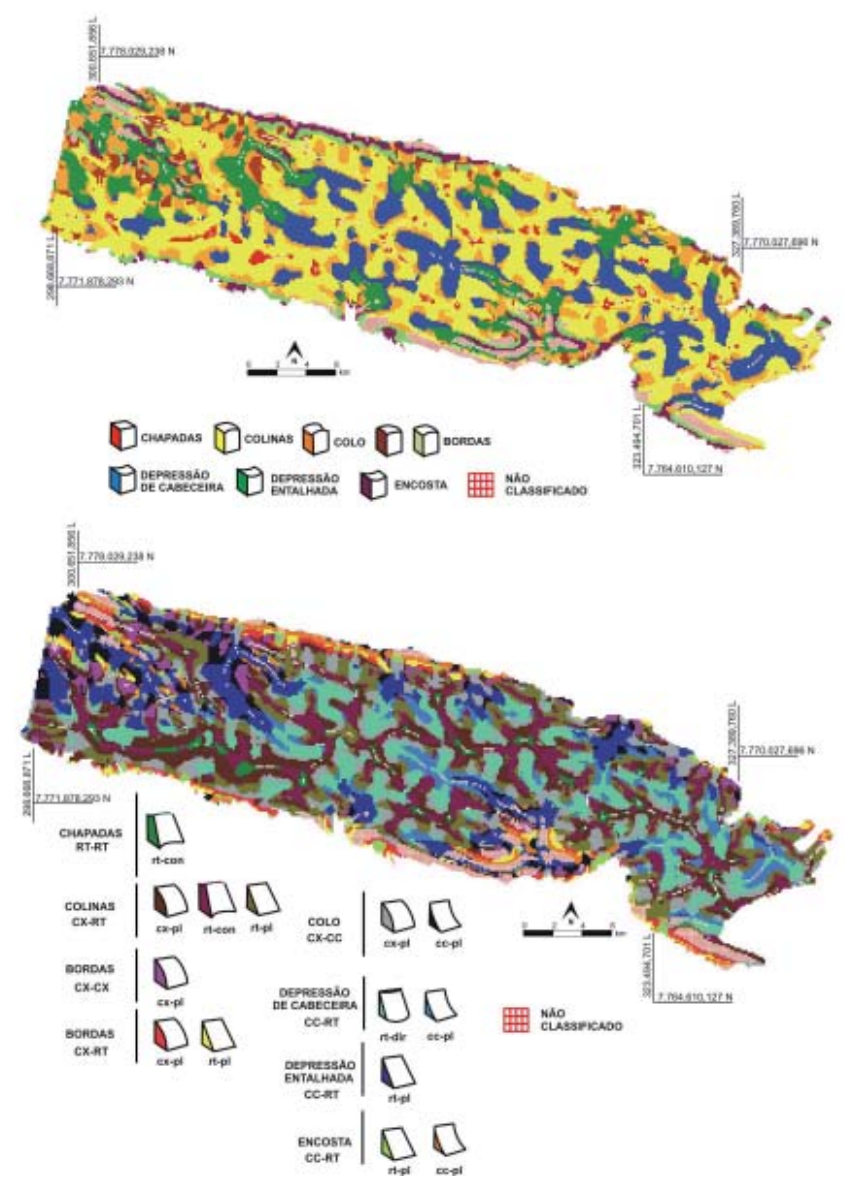

Figura 6 - Formas de Terreno e os seus respectivos Elementos.

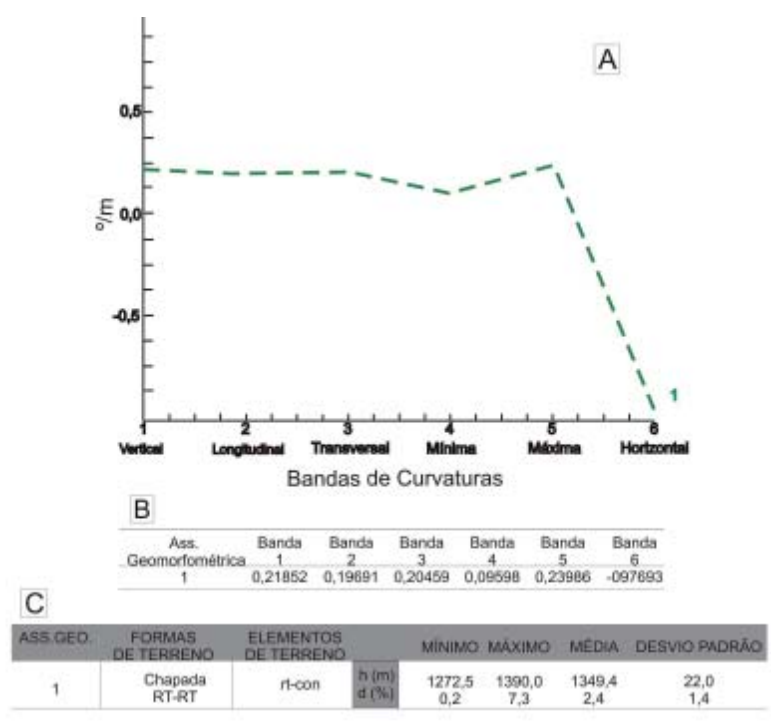

Figura 7 - Assinatura Geomorfométrica das Chapadas (A), Valores de Curvatura (B), Análise descritiva da Assinatura Geomorfométrica para Altimetria - h e Declividade - $d(C)$. 
As Colinas apresentam Formas de Terreno Convexo-Retilíneo (CX-RT) com Elementos de Terreno convexo-planar (cx-pl), retilíneo-convergente (rt-con), e retilíneo-planar (rt-pl). As Bordas são Formas de Terreno classificadas a partir das feições CX-RT e Convexo-
Convexo (CX-CX) associadas aos Elementos cx-pl e rt-pl. A CX-CX é caracterizada como um ambiente adjacente as Bordas CX-RT por estar mais a montante com valores altimétrico médios de $1233,4 \mathrm{~m}$ e declividade mais suave de $11,0 \%$ (Figuras 8 ).

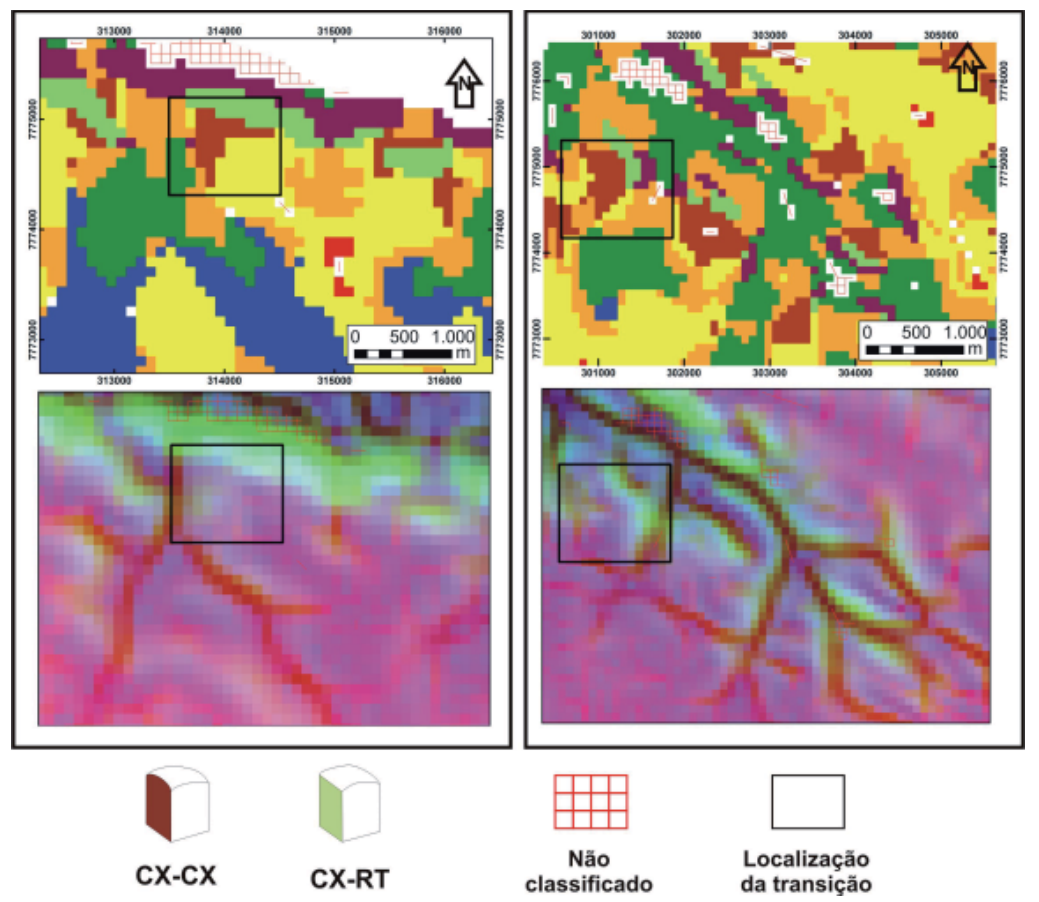

Figura 8 - Exemplos de transição entre as Bordas CX-CX e as Bordas CX-RT e respectiva composição colorida Altimetria (R) Declividade (G) Minima Curvatura (B).

Nesse sentido, o mesmo Elemento cx-pl é representado pelas Assinaturas Geomorfométricas 5 e 2 (Figura 9). Verifica-se que estas assinaturas apresentam Banda 1 de extrema convexidade com $0,89541 \%$ e $0,73970^{\circ} / \mathrm{m}$ respectivamente, mas na assinatura 5 há uma Banda $6 \mathrm{com}$ tendência a convergência $\left(-0,31841^{\circ} / \mathrm{m}\right)$.

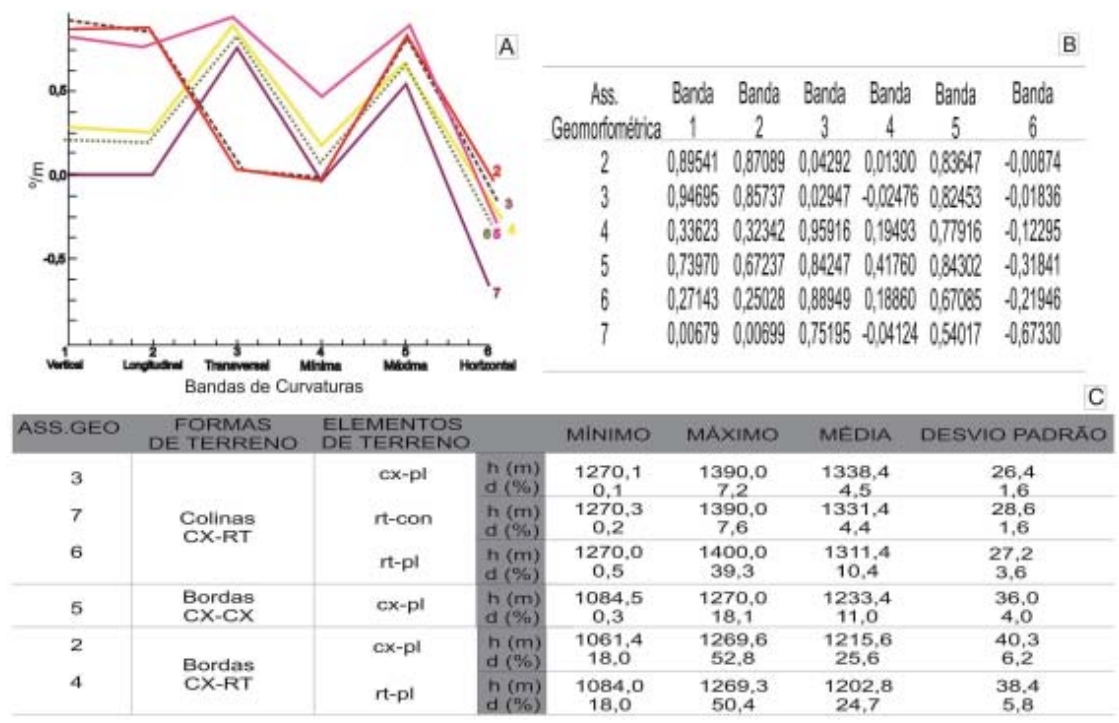

Figura 9 - Assinatura Geomorfométrica das Colinas e Bordas (A). Valores de Curvatura (B), Análise de descritiva da Assinatura Geomorfométrica para Altimetria - he Declividade $-d(C)$. 
Além disso, algumas similaridades espectrais são identificadas entre as Colinas e Bordas de mesma Forma de Terreno CX-RT, porém existe uma elevada variação de Altimetria (h) e de Declividade (d). Os valores altimétricos médio da cx-pl das Colinas são 1338,4m e das Bordas com 1215,6 $\mathrm{m}$. É importante salientar que em alguns setores observa-se a possibilidade de mistura tênue já que os valores mínimos alti- métricos do Elemento de Terreno para as Colinas (1270,1m) praticamente coincidem com os valores máximos da cx-pl localizado nas Bordas $(1270,0 \mathrm{~m})$. Entretanto, a declividade média da cx-pl das Bordas $(25,6 \%)$ é significantemente maior do que a apresentada nas Colinas $(4,5 \%)$ caracterizando relevos distintos (Figura 10).
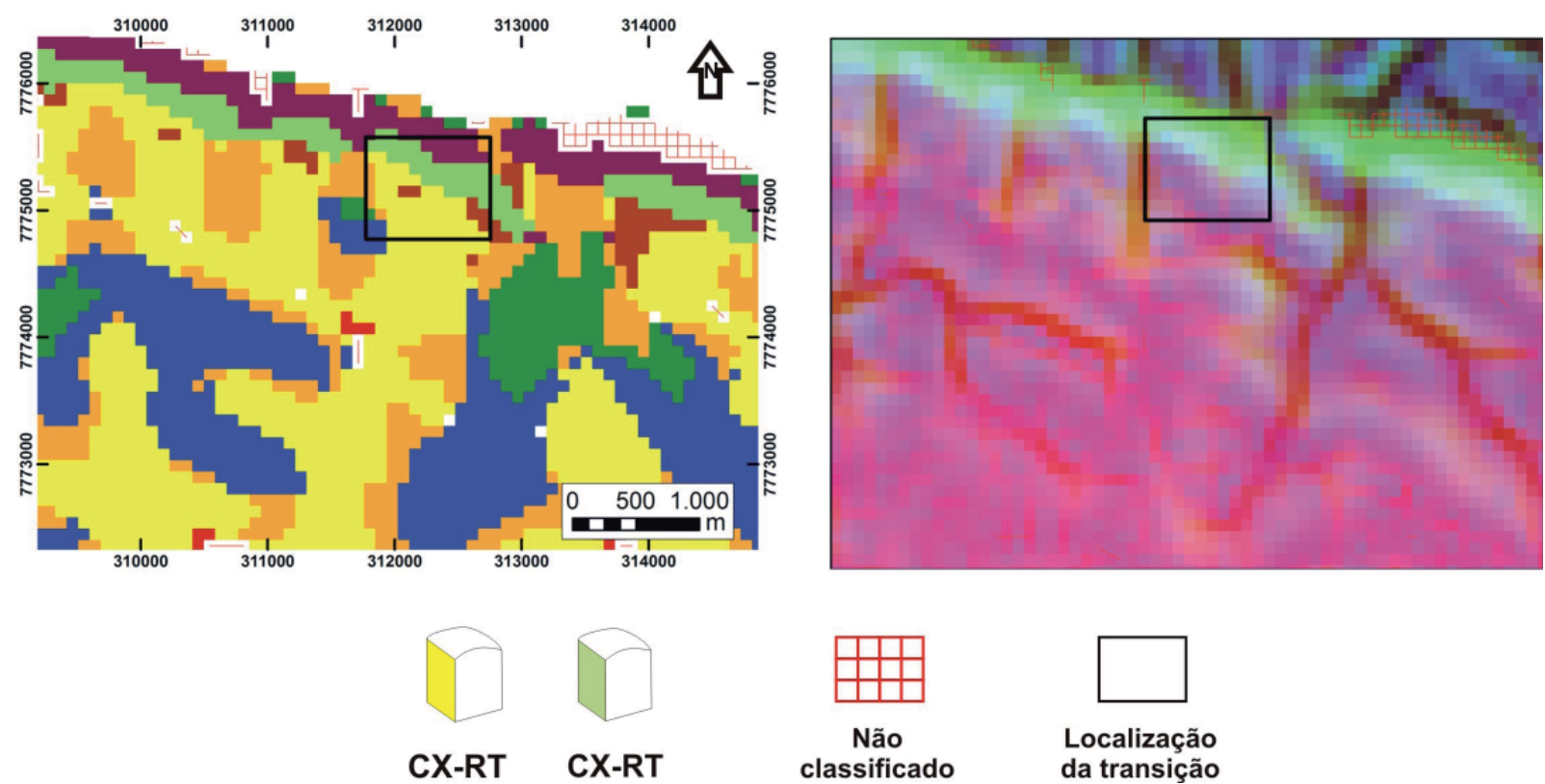

Figura 10 - Exemplo de transição entre Colinas $C X-R T$ e Bordas $C X$-RT e respectiva composição colorida Altimetria $(R)$ Declividade $(G)$ Minima Curvatura (B).

As assinaturas 6 e 4 também apresentam similaridade espectral apesar de estarem em FTs distintas. Observa-se apenas um ligeiro aumento de convexidade da assinatura 4 das Bordas CX-RT em todas as bandas em relação a assinatura 6. Contudo, a rt-pl das Bordas está no limite das escarpas do CZ com declividade média de $24,7 \%$ e a rt-pl para as Colinas localiza-se acima de 1270,0m e com declividade média de 10,4\%. Além disso, a malha espacial da rt-pl das Colinas pode ser abrangente quando se verifica os valores Máximos (1400,0m) e Mínimos de altimetria $(1270,0 \mathrm{~m})$ demonstrando inclusive valores Máximo superiores aos obtidos para a FT das Chapadas.

A assinatura 7 foi apresentada apenas na FT das Colinas. De maneira geral, o Elemento rt-con está localizado entre a cx-pl e a rt-pl com média altimétrica de $1331,4 \mathrm{~m}$ e com os menores valores de convexidade dentre os outros ETs. Pode ser também observado que o valor para a banda 6 de - 0,67330 $\%$ m possibilita a formação de canal de drenagem preferencial e regiões saturadas em água para os declives mais suaves.

As depressões são divididas em Depressão de Cabeceira, Depressão Entalhada e Encosta. Estas apresentaram a mesma Forma de Terreno Côncavo-Retilíneo (CC-RT) (Figura 11).
As assinaturas 8 e 12 da Depressão de Cabeceira proporcionaram valores praticamente nulos nas Bandas de Curvaturas Longitudinal e Máxima para Assinatura Geomorfométrica 8 e nas Bandas de Transversal e Máxima para a Assinatura 12. Na Depressão Entalhada verificam-se apenas valores negativos entre as bandas 2 e 5 demonstrando maior concavidade. As Encostas diferem das outras FTs, principalmente, porque detiveram valores positivos acima de 0,2000 $\%$ m nas Curvaturas Longitudinal para a Assinatura 10, na Transversal para Assinatura 11 e na Mínima Curvatura para ambas Assinaturas. Essa configuração mostra uma intensidade positiva elevada nas Encostas nas bandas 2 e 3 para uma Forma CC-RT caracterizando um possível processo de transição de Retilíneo a Convexo.

Com relação aos ETs são identificadas a retilíneodivergente (rt-dir), côncavo-planar (cc-pl) e retilíneo-planar (rt-pl). Os Elementos cc-pl e rt-pl são observadas tanto nas Depressões quanto nas Encostas onde a maior variação do valor da curvatura se encontra na Banda 1. A cc-pl apresenta maior concavidade na Curvatura Vertical na FT da Encosta. Entretanto, a rt-pl na Depressão Entalhada mostra um valor na Banda 1 de $-0,30395^{\circ} / \mathrm{m}$ e $0,30094^{\circ} / \mathrm{m}$ para a Banda 6 próximo ao valor limite que caracteriza um relevo rt-pl demonstrando, consequentemente, elevada concavidade e divergência. 


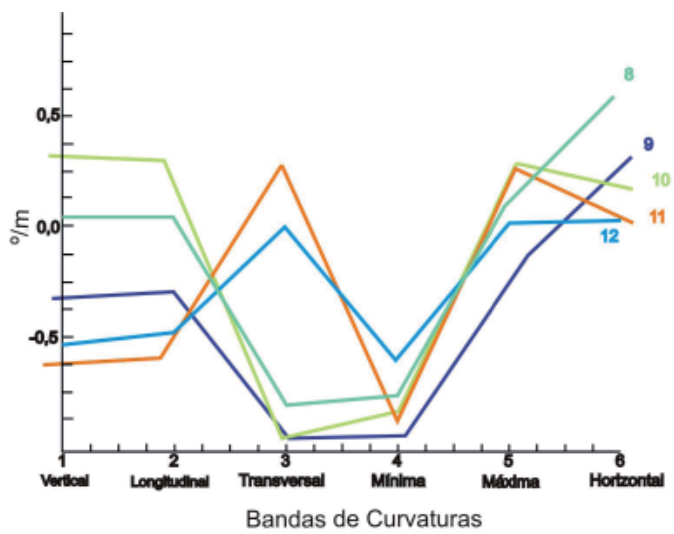

A

Ass. Banda Banda Banda Banda Banda Banda

$\begin{array}{lllllll}\text { Geomoromética } & 1 & 2 & 3 & 4 & 5 & 6\end{array}$

$8 \quad 0,09845 \quad 0,00568 \quad-0,74926 \quad-0,718710,080063 \quad 0,59423$

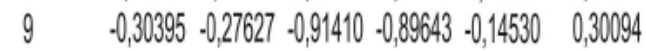

$\begin{array}{lllllll}10 & 0,25550 & 0,24317 & -0,88790 & -0,74974 & 0,23058 & 0,10167\end{array}$

$\begin{array}{lllllllll}11 & -0,07605 & -0,65097 & 0,22491 & -0,00880 & 0,20013 & -0,02930\end{array}$

$12 \quad-0,53495 \cdot 0,48326 \cdot 0,04542 \cdot 0,585260,011583 \quad 0,02120$

\begin{tabular}{|c|c|c|c|c|c|c|c|}
\hline ASS.GEO & FORMAS DO TERRENO & $\begin{array}{l}\text { ELEMENTOS } \\
\text { DO TERRENO }\end{array}$ & & MiNIMO & MÁXIMO & MÉDIA & DESVIO PADRĀO \\
\hline 8 & \multirow{2}{*}{$\begin{array}{c}\text { Depressão de Cabeceira } \\
\text { CC-RT }\end{array}$} & rt-dir & $\begin{array}{l}\text { h }(m) \\
\text { d }(\%)\end{array}$ & $\begin{array}{c}1270,1 \\
0.3\end{array}$ & $\begin{array}{c}1385,0 \\
7.3\end{array}$ & $\begin{array}{c}1312,0 \\
5,1\end{array}$ & $\begin{array}{c}24,8 \\
1,4\end{array}$ \\
\hline 12 & & cC-pl & $\begin{array}{l}\text { h }(m) \\
\text { d }(\%)\end{array}$ & $\begin{array}{c}1270,0 \\
7,0\end{array}$ & $\begin{array}{c}1374,0 \\
24,7\end{array}$ & $\begin{array}{c}1296,7 \\
11,1\end{array}$ & $\begin{array}{l}17,6 \\
3,0\end{array}$ \\
\hline 9 & $\begin{array}{l}\text { Depressão Entalhada } \\
\text { CC-RT }\end{array}$ & rt-pl & $\begin{array}{l}\text { h }(m) \\
\text { d (\%) }\end{array}$ & $\begin{array}{c}1046,8 \\
0,3\end{array}$ & $\begin{array}{c}1270,0 \\
18,5\end{array}$ & $\begin{array}{c}1211,3 \\
9,4\end{array}$ & $\begin{array}{c}54,2 \\
4,0\end{array}$ \\
\hline 10 & \multirow[b]{2}{*}{$\begin{array}{l}\text { Encosta } \\
\text { CC-RT }\end{array}$} & $\mathrm{rt}-\mathrm{pl}$ & $\begin{array}{l}\text { h }(m) \\
\text { d }(\%)\end{array}$ & $\begin{array}{c}1053,0 \\
18,0\end{array}$ & $\begin{array}{c}1267,1 \\
52,0\end{array}$ & $\begin{array}{c}1183,6 \\
23,6\end{array}$ & $\begin{array}{c}39,8 \\
4,8\end{array}$ \\
\hline 11 & & cc-pl & $\begin{array}{l}\text { h }(m) \\
\text { d }(\%)\end{array}$ & $\begin{array}{c}1047,2 \\
18,0\end{array}$ & $\begin{array}{c}1269,8 \\
52,5\end{array}$ & $\begin{array}{c}1161,3 \\
25,1\end{array}$ & $\begin{array}{c}46,1 \\
6,1\end{array}$ \\
\hline
\end{tabular}

Figura 11 - Assinatura Geomorfométrica das Depressões e Encostas (A), Valores de Curvatura (B) e Análise descritiva da Assinatura Geomorfométrica para Altimetria - h e Declividade - d (C).

O Elemento rt-dir aparece como um ambiente de topo das Depressões com declividade variando entre $0,3 \%$ e 7,3\%. Em seguida, a forma cc-pl promove um aumento da declividade média com 11,1\%. Apesar da diminuição da declividade na Forma rt-pl $(9,4 \%)$ localizada na Depressão Entalhada, é verificada as maiores variações entre os valores Mínimos e Máximos de declividade com $0,3 \%$ e $18,5 \%$ respectivamente. Nas Encostas, a rt-pl localiza-se no topo com declividade média de $23,6 \%$ chegando a $52,0 \%$. Na forma seguinte (ccpl) é verificado um pequeno aumento da declividade média com $25,1 \%$.

Os Colos, que são caracterizados por uma feição Convexo-Concâvo (CX-CC), são observados dois Elementos de Terreno: convexo-planar (cx-pl) e côncavo-planar (cc-pl) (Figura 12).

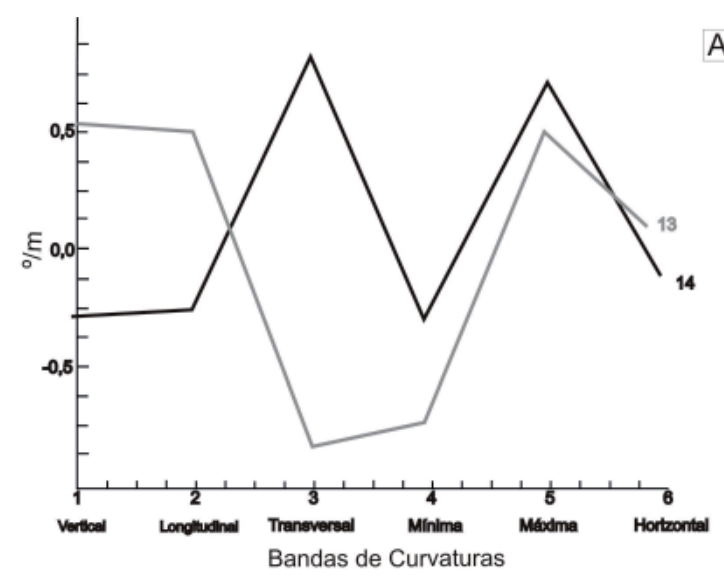

A

\section{B}

\begin{tabular}{ccccccc} 
Ass. & Banda & Banda & Banda & Banda & Banda & Banda \\
Geomofométicaca & 1 & 2 & 3 & 4 & 5 & 6 \\
\hline 13 & 0,51565 & 0,47621 & $-0,78967$ & $-0,07603$ & 0,45048 & 0,16913 \\
14 & $-0,33923$ & $-0,33504$ & 0,033063 & $-0,35574$ & 0,63396 & $-0,18315$ \\
\hline
\end{tabular}

\begin{tabular}{|c|c|c|c|c|c|c|}
\hline ASS.GEO & $\begin{array}{l}\text { FORMAS } \\
\text { DE TERRENO }\end{array}$ & $\begin{array}{l}\text { ELEMENTOS } \\
\text { DE TERRENO }\end{array}$ & MíNIMO & MÁXXIMO & MÉDIA & DESVIO Ph \\
\hline 13 & Col & 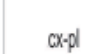 & $\begin{array}{c}1061,0 \\
0,7\end{array}$ & $\begin{array}{c}1395,0 \\
44,3\end{array}$ & $\begin{array}{c}1291,3 \\
10,7\end{array}$ & $\begin{array}{c}52,6 \\
3,9\end{array}$ \\
\hline 14 & $C X-C C$ & & $\begin{array}{c}0,1 \\
1067,0 \\
0,1\end{array}$ & $\begin{array}{c}1270,0 \\
18,2\end{array}$ & $\begin{array}{c}1201,3 \\
11,6\end{array}$ & $\begin{array}{l}5,9 \\
3,0 \\
3,8\end{array}$ \\
\hline
\end{tabular}

Figura 12 - Assinatura Geomorfométrica dos Colos (A), Valores de Curvatura (B), Análise descritiva da Assinatura Geomorfométrica para Altimetria - h e Declividade - $d(C)$. 
A Assinatura Geomorfométrica 13 possui valores extremamente baixos nas Bandas $3\left(-0,78967^{\circ} / \mathrm{m}\right)$ e 4 $\left(-0,67603^{\circ} / \mathrm{m}\right)$, onde se sugere um aspecto de concavidade profundas e convexidades mais amena, entretanto o Elemento de Terreno classificado a partir da Curvatura Vertical e Horizontal é a cx-pl. Esta forma apresenta a maior variação de declividade com valores mínimos de $0,7 \%$ e valores máximos de $44,3 \%$. Isto pode ser explicado pela grande variação altimétrica $(1061,0 \mathrm{~m} / 1395,0 \mathrm{~m})$ o que demonstra a diversidade da malha espacial dos Colos estando adjacente, basicamente, a todas as Formas de Terreno classificadas.

Com relação à assinatura 14 , identifica-se que as Bandas 2 e 4 detiveram os valores mínimos para caracterizar um ambiente côncavo de $-0,33504$ \% $/ \mathrm{m}$ e $-0,35574$

$\% / \mathrm{m}$ respectivamente, atribuindo ao relevo uma fisionomia de concavidade suave. Essa análise ainda é corroborada pelos valores da Curvatura Vertical $(-0,33923 \% \mathrm{~m})$ que também apresentam valores mínimos para se configurar um ET de aspecto côncavo. Além disso, verifica-se que a malha espacial da cc-pl se apresenta mais localizada entre $1067,0 \mathrm{~m}$ e $1270,0 \mathrm{~m}$ com uma declividade entre $0,1 \%$ e $18,2 \%$.

A partir da classificação espectral, as 14 Assinaturas Geomorfométricas demonstram variação de intensidade e/ou de localização dos Elementos de Terreno dentro de uma respectiva Forma de Terreno. Além disso, a Análise Descritiva facilitou a compreensão do posicionamento das vertentes e dos limites entre os Elementos decorrente dos níveis de dissecação e das informações altimétricas (Tabela 4).

Tabela 4 - Análise Descritiva da Altimetria (m) e Declividade (\%).

\begin{tabular}{|c|c|c|c|c|c|c|c|c|c|c|}
\hline Id & FTs & $\begin{array}{c}\text { Assinatura } \\
\text { Geomorfométrica }\end{array}$ & MINIMO (m) & MÁxIMO (m) & MÉDIA (m) & $\begin{array}{r}\text { DESVIO } \\
\text { PADRÃO }\end{array}$ & MINIMO (\%) & MÁxIMO(\%) & MÉDIA (\%) & $\begin{array}{l}\text { DESVIO } \\
\text { PADRÃO }\end{array}$ \\
\hline 1 & Chapadas & RT-RT_rt-dir & 1272,5 & 1390,0 & 1349,4 & 22,0 & 0,2 & 7,3 & 2,4 & 1,4 \\
\hline 2 & \multirow{3}{*}{ Colinas } & CX-RT_CX-pl & 1270,1 & 1390,0 & 1338,4 & 26,4 & 0,1 & 7,2 & 4,6 & 1,7 \\
\hline 3 & & CX-RT_rt-con & 1270,3 & 1389,9 & 1331,5 & 28,6 & 0,2 & 7,6 & 4,4 & 1,6 \\
\hline 4 & & CX-RT_rt-pl & 1270,0 & 1400,0 & 1311,5 & 27,3 & 0,5 & 39,3 & 10,4 & 3,6 \\
\hline 5 & Depresão de & CC-RT_rt-dir & 1270,1 & 1385,1 & 1311,9 & 24,8 & 0,3 & 7,3 & 5,1 & 1,4 \\
\hline 6 & Cabeceira & CC-RT_cc-pl & 1270,0 & 1373,9 & 1296,7 & 17,6 & 0,8 & 7,2 & 5,3 & 1,4 \\
\hline 7 & $\begin{array}{l}\text { Depresão } \\
\text { Entalhada }\end{array}$ & CC-RT_rt-pl & 1046,8 & 1270,0 & 1211,3 & 54,2 & 0,3 & 18,5 & 9,4 & 3,9 \\
\hline 8 & \multirow[t]{2}{*}{ Colos } & CX-CC_cx-pl & 1061,0 & 1394,9 & 1291,3 & 52,6 & 0,7 & 18,4 & 10,7 & 3,9 \\
\hline 9 & & CX-CC_cc-pl & 1067,0 & 1270,0 & 1201,3 & 56,0 & 0,2 & 18,3 & 11,6 & 3,9 \\
\hline 10 & \multirow{3}{*}{ Bordas } & CX-CX_cx-pl & 1084,5 & 1269,9 & 1233,4 & 35,9 & 0,3 & 18,1 & 11,0 & 3,9 \\
\hline 11 & & CX-RT_cX-pl & 1061,4 & 1269,6 & 1215,6 & 40,3 & 17,9 & 52,9 & 25,6 & 6,3 \\
\hline 12 & & CX-RT_rt-pl & 1084,0 & 1269,4 & 1202,8 & 38,5 & 17,9 & 50,5 & 24,7 & 5,8 \\
\hline 13 & \multirow{2}{*}{ Encostas } & CC-RT_rt-pl & 1052,9 & 1267,1 & 1183,7 & 39,9 & 17,9 & 52,0 & 23,6 & 4,9 \\
\hline 14 & & CC-RT_cc-pl & 1047,2 & 1269,9 & 1161,3 & 46,2 & 17,9 & 52,5 & 25,1 & 6,1 \\
\hline
\end{tabular}

O princípio básico na análise de vertentes é reconhecer que os perfis podem ser caracterizados por mudanças suaves ou rupturas ao longo de linhas reconhecíveis de inflexão (Pitty, 1969). Giles e Franklin (1998) descrevem um procedimento para o particionamento de perfis bidimensionais em ambientes geomorfológico chamados de unidade de inclinação. Shary et al., (2005) a partir da área de contribuição, área de dispersão e dos extremos de profundidade e altitude, apresentam como montanhas, depressões e colos sem sobreposição. Minar e Evans (2008) propõem utilizar linhas singulares (singular line), pontos com extremos geomorfológicos e linhas de inflexão para definir os limites entre os segmentos das ETs

Observa-se na tabela 4 que os valores Mínimos, Máximos e Médias de altimetria sugerem ora continuidade e ora descontinuidade de limites a partir do acréscimo da declividade do topo para a base (Figura 13). Nas Colinas
(Id - 4) apesar da declividade média de 10,4\% mostram valores Máximos de 39,3\% podendo ser confundidos com as Formas de Terreno de Borda (Id- 12). As Depressões Entalhadas aparecem com diferentes níveis de dissecação com mistura de limite com as Depressões de Cabeceira verificadas pelos valores Mínimos de declividade 0,3\% e o Desvio Padrão de Altimetria de 54,2\%. Os Colos são as FTs que apresentam a malha espacial mais abrangente verificada a partir dos maiores valores de Desvio Padrão de Altitude dentre todas as formas.

Além disso, a informação espectral pode caracterizar uma sequência de Elementos de Terreno em uma ou mais Formas de Terreno de acordo com a variação da intensidade de cada pixel apesar de cada um deles ser caracterizado por uma mistura espectral de curvaturas (Figura 14). 
Sistema de classificação geomorfométrica baseado em uma arquitetura sequencial em duas etapas: árvore de decisão e classificador...
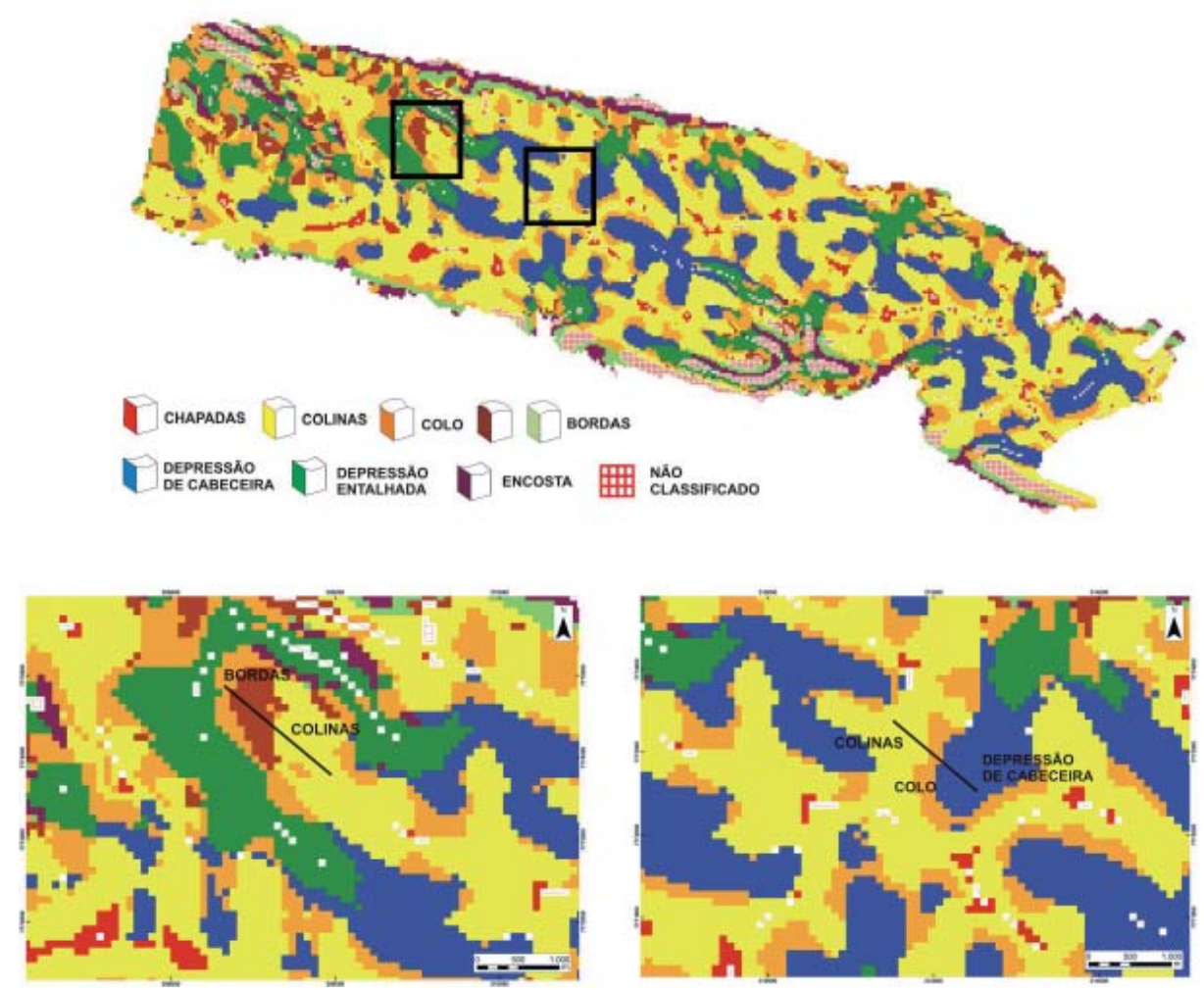

Figura 13 - Exemplo de descontinuidade abrupta entre bordas e colinas (à esquerda) e descontinuidade suave entre colinas, colos e Depressão de Cabeceira (à direita).
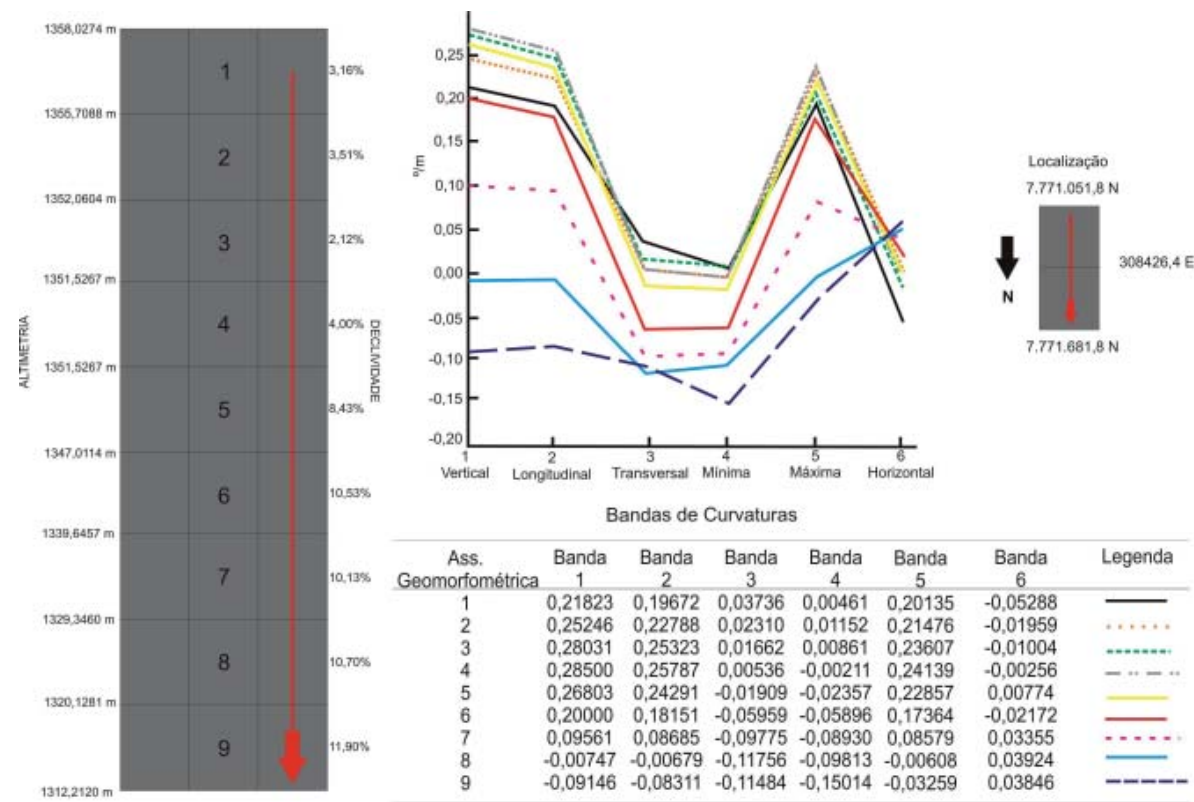

Figura 14 - A distribuição dos espectros em uma sequência linear mostrando a variação do relevo pixel a pixel. 
A distribuição dos espectros ao longo de uma vertente demonstra uma variação contínua de uma Forma RT-RT com predominância de Elementos retilíneo-planar (rt-pl). Entre as assinaturas 1 e 5, a FT relacionada recebe um acréscimo de valores nas curvaturas Longitudinal (Banda 2) e Máxima (Banda 5); e um decréscimo mais suavizado nas curvaturas Transversal (Banda 3) e Mínima (Banda 4). Pode-se inferir que as Chapadas apresentam uma variação progressiva do relevo no sentido dos Colos, com provável passagem pela Forma das Colinas. A curvatura Horizontal (Banda 6) apresenta uma pequena variação positiva, mas caracteriza mais uma estabilidade do que realmente uma mudança, porém as curvaturas Verticais (Banda 1) se tornam cada vez mais convexas.

A ruptura de relevo se dá a partir da assinatura 5 (cor amarela) com 8,43\% de declividade. Entre as assinaturas 6 e 9 o decréscimo dos valores são mais abruptos especialmente na curvatura Longitudinal e Máxima. Nesse sentido, a paisagem local volta a estar mais retilíneo, porém com o constante processo de abatimento. A curvatura Horizontal apresenta acréscimos caracterizando uma drenagem paulatinamente mais divergente.

\section{Conclusão}

Neste trabalho é proposto um método para o mapeamento das Formas de Terreno e dos Elementos de Terreno a partir de uma imagem SRTM de $\sim 90 \mathrm{~m}$. Na metodologia proposta devem-se salientar os seguintes aspectos: (a) análise considerando as diferenças entre os dados de altimetria e de suas derivadas; (b) emprego de duas etapas de análise com métodos e dados diferenciados onde a segunda classificação é uma subdivisão da primeira, (c) na segunda etapa realiza-se uma classificação considerando assinaturas geomorfométricas a partir de todos os tipos de curvatura. Desta forma, o método estabelece uma análise hierárquica que considera uma primeira classificação dos dados de altimetria e declividade ( $1^{\circ}$ derivada $)$ e uma segunda etapa que proporciona uma subdivisão das classes inicialmente identificadas a partir dos atributos de curvatura $\left(2^{\circ}\right.$ derivada). Esta subdivisão hierárquica proporciona identificar ambientes homogêneos considerando diferentes variações do relevo.

A classificação espectral adotando assinaturas geomorfométricas permitiu uma maior flexibilidade na definição das formas de relevo com relevância na área de estudo. De forma análoga ao agrupamento das imagens multibandas de sensores remotos, as seis imagens de curvatura do terreno são unidas estabelecendo para cada célula um espectro geomorfométrico, que permite caracterizar o ambiente em que está inserido. As curvas são individualizadas tanto pelo comportamento relativo entre os atributos de curvatura, mas também pela intensidade desta relação. O método por ser computacional permite o mapeamento de extensas áreas de forma rápida e padronizada.

Em uma primeira análise a área de estudo pode ser considerada um ambiente relativamente plano e preservado do ponto de vista erosivo, pois apresenta uma média baixa aproximada de $12 \%$ de declividade com uma variação altimétrica de $1046,8 \mathrm{~m}$ até $1400 \mathrm{~m}$. Porém, a classificação das Formas de Terreno por meio da assinatura geomorfométrica permitiu visualizar níveis de dissecação. O Chapadão do Zagaia apresenta aproximadamente 49,21\% de ambientes côncavos (Depressão de Cabeceira e Entalhada) 15,80\% de ambientes de transição (Colos) e 35,1\% de ambientes convexos e planos (Chapadas, Colinas e Bordas). Nesse sentido, é possível inferir que há uma sobreposição das Depressões e Colos em relação às Chapadas e Colinas, ou seja, as Formas de Terreno demonstram um elevado estágio de dissecação nessa porção da Serra da Canastra.

Além disso, o detalhamento das Formas de Terreno permitiu visualizar os seus Elementos e consequentemente o comportamento da sua vertente organizada em uma topossequência. A forma tridimensional da vertente indica padrões de direção de fluxo que condicionam a transformação da paisagem de maneira físico-química.

Não cabe ao método apresentado promover uma discussão sobre o tipo de processo que a área está sujeita. Porém, o mapa de Formas de Terreno e de seus Elementos pode auxiliar na escolha de áreas representativas para estudos pedogeomorfológicos, geobotânicos, evolução do relevo junto as suas componentes estruturais, paleoclimáticas e hidrogeológicas. Assim, a identificação de formas similares evidencia fatores de gênese comum que auxilia na formulação de modelos e compreensão dos sistemas presentes na paisagem.

\section{Agradecimentos}

Ao CNPq pela bolsa de pós-graduação, a FINATEC pela participação em eventos e ao Laboratório de Informações Espaciais - LSIE da Universidade de Brasília - UnB.

\section{Referências Bibliográficas}

AB' SÁBER, A. N. Províncias geológicas e domínios morfoclimáticos no Brasil. Geomorfologia, São Paulo, n. 20, p. 1-26.1970.

ALMEIDA, F. F. M. O Cráton do São Francisco. Revista Brasileira de Geociências,. v.7, n. 4, p. 349-364. 1977.

ANA. A Evolução da Gestão dos Recursos Hídricos no Brasil. Agência Nacional de Águas. Brasília, p.68 2002.

BOARDMAN, J. W.; KRUSE, F. A. Automated spectral analysis a geological example using AVIRIS data, North 
Grapevine, Mountains, Nevada. Proceedings of the Tenth Thematic Conference on Geological Remote Sensing. San Antonio: [s.n.]. 1994. p. 407-418.

BORGES, M. E. S. CARVALHO JUNIOR, O. A; MARTINS, E. S.; ARCOVERDE, G. F. B.; GUIMARÃES, R. F.; GOMES, R. A. T. Emprego do processamento digital dos parâmetros morfométricos no mapeamento geomorfológico da bacia do Rio Preto. Espaço e Geografia, Brasília, v. 10, n. 2, p.279-294. 2007.

BRASIL. PROJETO RADAMBRASIL. Levantamento de Recursos Naturais Folhas SF. 23/24 Rio de Janeiro/Vitória. Ministério das Minas e Energia. Brasília, DF, 1983. p. 56-66.

BROWN, D.G.; LUSCH, D.P. DUDA, K.A.Supervised classification of types of glaciated landscapes using digital elevation data. Geomorphology. v. 21, n. 3-4, p. 233250.1998 .

CARVALHO JÚNIOR, O. A.; MARTINS, E. S.;GUIMARÃES, R. F.; CARVALHO, A. P. F. Compartimentação Geomorfológica do Parque Nacional da Chapada dos Veadeiros Baseado em técnica de Geoprocessamento. Boletim de Pesquisa da Embrapa Cerrados, Planaltina, 2001. v. 34. p. 1-18.

COUTO JUNIOR, A. F.; SOUZA, V. V.; CARVALHO JUNIOR, O. A.; MARTINS, E. S.; SANTANA, O. A.; FREITAS, L. F. GOMES, R. A. T. Integração de parâmetros morfométricos e imagem aster para a delimitação das fitofisionomias da serra da canastra, parque nacional da serra da canastra, MG. Revista Brasileira de Geomorfologia, v. 11,n. 1, p. 57-68. 2010.

DRAGUT, L.; BLASCHKE, T. Automated classification of landform elements using object-based image analysis. Geomorphology, v. 81, p.330-344. 2006.

EVANS, I. S. An integrated system of terrain analysis and slope mapping. Zeitschrift für Geomorphologie, Supplementband, Johannesstr, v. 36, [s.n.], p. 274-295. 1979.

EVANS, I. S.; HENGL, T.; GORSEVSKI, P. Aplications in Geomorphology. In: HENGL, T.; REUTER, H. I. Geomorphometry. 1.ed. Amsterdam: Elsevier, v. 33, 2009. Cap. 22, p. 497-525.

EVANS, I. S. Correlation structures and factor analysis in the investigation of data dimensionality: statical properties of the Wessex land surface. International Symposium on Spatial Data Handling. Zürich: Universität Zürich. 1984. p. 98-116.

EVANS, L. S.; MCCLEAN, C. J. The land surface is not unifractal: variograms, cirque scale and allometry. Zeitschrift für Geomorphologie, v. 101, p. 127-147. 1995.

EVANS, I. S. General geomorphometry, derivations of altitude and descriptive statistics. In: Spatial Analysis in Geomorphology, Chorley, R. J. (Ed.). British Geomorphological Research Group, 17 - 90 (Cap.2). 1972. 399p.

FARR, T. G.; ROSEN, P. A.; CARO, E.; CRIPPEN, R.; DUREN, R.; HENSLEY, S.; KOBRICK, M.; PALLER, M.; RODRIGUEZ,
E.; ROTH, L.; SEAL, D.; SHAFFER, S.; SHIMADA, J.; UMLAND, J.; WENER, M.; OSKIN, M.; BURBANK, D.; ALSDORF, D. The Shuttle Radar Topography Mission. Review in Geophysics, v. 45, n. 2, p. 21-35, 2007

GILES, P. T.; FRANKLIN, S. E. An automated approach to the classification of slope unit using digital data. Geomorphology, v. 22 , i. 3-4, p. 251-264.1998.

GUIMARÃES, R. F.; CARVALHO JÚNIOR, O. A.; MARTINS, E. S.; CARVALHO, A. P. F.; GOMES, R. A. T. Detection of karst depression by aster image in the Bambui Group, Brazil. In: Remote Sensing Symposium - SPIE, 2005, Brugges, Belgium. Proceeding of the SPIE - Remote Sensing for Environmental Monitoring, GIS Applications, and Geology. 2005. v. 5983. p. $1-12$.

HERMUCHE, P. M.;ANDRADE, A. C.; GUIMARÃES, R. F.; LEAL, L. R.; CARVALHO JUNIOR, O. A.; MARTINS, E. S. Compartimentação geomorfológica em escala regional da bacia do rio Paranã. Geouerj, n. 1, p. 372-381. 2003.

HUTCHINSON, M. F. A new procedure for gridding elevation and stream line data with automatic removal of spurious pit. Journal of Hydrology, v. 106, n. 3-4, p. 211-232. 1989.

ICMBIO. Plano de Manejo do Parque Nacional da Serra da Canastra. Instituto Chico Mendes de Conservação da Biodiversidade. Brasilia, p. 799p. 2005.

JARVIS, A.; RUBIANO, J; NELSON, A; FARROW, A; MULLIGAN, M. Practical use of SRTM data in the tropics: comparisons with digital elevation models generated from cartographic data. Cali: Centro Internacional de Agricultura Tropical, 2004. 31p

Lane, S.N., Richards, K.S., Chandler, J.H. (ed.). Landform Monitoring, Modelling and Analysis. Chichester: Wiley, 1998. 466 p.

KRUSE, F. A.; LEFKOFF, A. B.; BOARDMAN, J. W.; HEIEDBRECHT, K. B.; SHAPIRO, A. T.; BARLOON, P. J.; GOETZ, A. F. H. The spectral image processing system (SIPS) - Interactive visualization and analysis of imaging spectrometer data. Remote Sensing of Environment,v. 44, p. 437-456. 1993.

LATORRE, M. L.; CARVALHO JUNIOR, O. A.; SANTOS, J. R.; SHIMABUKURO, Y. E. Integração de dados de sensoriamento remoto multiresoluções para a representação da cobertura da terra utilizando campos contínuos de vegetação e classificação por árvores de decisão. Revista Brasileira de Geofísica, v. 25, p. 63-74. 2007.

LU, Z.; RYKHUS, R., MASTERLARK, T., DEAN, K. G. Mapping recent lava flows at Westdahl Volcano, Alaska, using radar and optical satellite imagery. Remote Sensing of Environment, v. 91, n. 3-4, p. 345-353. 2004.

MACMILLAN, R. A.; SHARY, P. A. Landforms and Landform Elements in Geomorphometry. In: HENGL, T.; REUTER, H. 
I. Geomorphometry: Concepts, Software, Applications. Elsevier, v. 33, 2009. Cap. 9, p. 227-254.

MARTINS, E. S.; CARVALHO JÚNIOR, O. A.; SOUZA, V. V.; COUTO JUNIOR, A. F.; OLIVEIRA, S. N.; GOMES, R. A. T.; REATTO, A. Relação Solo-Relevo em Vertentes Assimétricas no Parque Nacional da Serra dos Órgãos, RJ. Revista Brasileira de Geomorfologia, Rio de Janeiro, v. 8, p. 45-62. 2007.

MINÁR, J.; EVANS, E. Elementary forms for land surface segmentation: The theoretical basis of terrain analysis and geomorphological mapping. Geomorphology, v. 95, p. 236259. 2008.

OLIVEIRA, S. N.; CARVALHO JÚNIOR, O. A.; MARTINS, E. S.;SILVA, T. M.; GUIMARÃES, R. F.; GOMES, R. A. T. Identificação de Unidade de Paisagem e sua implicação no Parque Nacional da Serra dos Órgãos, Rio De Janeiro. Revista Brasileira de Geomorfologia, Porto Alegre, 2007. v. 8, p. 89-108.

PELOSO, B. D. D. A.; SHIMABUKURO, Y. E. Caracterização de unidades geo-botânicas do parque nacional da serra do cipó (MG) através da integração de imagens ópticas e modelo digital de elevação. Revista Brasileira de Cartografia, Rio de Janeiro, n. 62/1, p.103-118. 2010.

PIKE, R.J. The geometric signature: quantifying landslideterrain types from digital elevation models. Mathematical Geology, v. 20, 491-511. 1988.

PIKE, R.J. Geomorphometry - diversity in quantitative surface analysis. Progress in Physical Geography, v. 24, n. 1, p. 1-20. 2000.

PIKE, R. J.; EVANS, I. S.; HENGL, T. Geomorphometry: A Brief Gudie. In: HENGL, T.; REUTER, H. I. Geomorphometry: Concepts, Softwares, Applications. $1^{\circ}$ Edição. ed. Amsterdam: Elsevier, v. 33, 2009. Cap. 1, p. 3-30.

PITTY, A. F. A Scheme for Hillslope Analysis. Yorkshire: University of Hull Publication, 1969. 76p.

RABUS, B.; EINEDER, M.; ROTH, A.; BAMLER, R. The suttle radar topography mission - a new class of digital elevation models acquired by spaceborne radar. Journal of Photogrammetry \& Remote Sensing, v. 57, p. 241-262. 2003.

ROMERO, R.; NAKAJIMA, J. N. Espécies endêmicas do Parque Nacional da Serra da Canastra. Revista Brasileira de Botânica. São Paulo, v. 22, n. 2, p. 259-265. 1999.

ROSS, J. L. S. Ecogeografia do Brasil: Subsídios para planejamento ambiental. São Paulo: Oficina de Texto, 2006. p.111.

SCHMIDT, J.; HEWITT, A. Fuzzy land element classification from DTMs based on geometry and terrain position. Geoderma, v. 121 , i. $3-4$, p. $243-256.2004$.
SHARY, P. A.; SHARAYA, L. S.; MITUSOV, A. V. The problem of scale-specific and scale-free approaches in geomorphometry. Geografia Física e Dinâmica Quaternária, v. 28, n. 1, p. 81101. 2005.

SHIMIDT, J.; DIKAU, R. Extracting geomorphometric attributes and objects from digital elevation models - semantics, methods, future needs. In: DIKAU, R.; SAURER, H. GIS for Earth Surface Systems - Analysis and Modelling of the Natural Environment. Stuttgart: Berlin: Gebrüder Borntraeger, 1999. p. 153-173.

SMITH, B.; SANDWELL, D. Accuracy and resolution of Shuttle Radar Topography Mission data. Geophysical Research Letters, v. 30, n. 9, 1467, 2003.

SMITH, M. P.; ZHU, A. X.; BURT, J. E.; STILES, C. The effects of DEM resolution and neighborhood size on digital soil survey. Geoderma, v. 137, p. 58-68. 2006.

SOUZA, S. M. T. (Coord). Deflúvios Superficiais no Estado de Minas Gerais. Belo Horizonte: Hidrosistemas \& COPASA/ MG, 1993, 264p.

VALERIANO, C. D. M.; AIMEIDA, J. C. H.; SIMÕES, L. S. A.; DUARTE, B. P.; ROIG, H. L.; HEILBRON, M. Evolução estrutural do Domínio Externo da Faixa Brasília no Sudoeste de Minas Gerais: Registros de Uma Tectônica Pré-Brasiliana. Revista Brasileira de Geociências, v. 25, n. 4, p. 221-234, dez. 1995.

VALERIANO, C. D. M.; DARDENNE, M. A.; FONSECA, M. A.; SIMÕES, L. S. A.; SEER, H. J.A evolução tectônica da Faixa Brasília. In: MANTESSO-NETO, V.; BARTORELLI, A.; CARNEIRO, C. D. R.; BRITO-NEVES, B. B. Geologia do Continente Sul-Americano: Evolução da Obra de Fernando Flávio Marques de Almeida. Ed. Beca, 2004. Cap. 23, p. 575-592.

VALERIANO, M. D. M.; CARVALHO JUNIOR, O. A. D. Geoprocessamento de Modelos Digitais de Elevação para Mapeamento da Curvatura Horizontal em Microbacias. Revista Brasileira de Geomorfologia, Uberlândia, v. 4 n. 1, p. 17-29, 2003.

VAN ZYL, J. J. The Shuttle Radar Topography Mission (SRTM): a breakthrough in remote sensing of topography. Acta Astronautica, v. 48, n. 5, p. 559-565, março/junho2001.

WOOD, J. The Geomorphological Characterisation of Digital Elevation Models.1996. 184 f. Thesis (PhD in Science Information) - Science Information Department, University of Leicester, Leicester. 